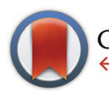

CrossMark

$\leftarrow$ click for updates

Cite this: Dalton Trans., 2015, 44 2953

Received 11th November 2014, Accepted 1st December 2014

DOI: $10.1039 / c 4 d t 03462 g$

www.rsc.org/dalton

\section{Divalent ytterbium complexes with crown and heterocrown ethers $\dagger$ t}

\author{
Philip N. Bartlett, Martin J. D. Champion, Mark. E. Light, William Levason,* \\ Gillian Reid and Peter W. Richardson
}

Several unusual complexes of ytterbium(II) stabilised by coordination to mixed $\mathrm{O}_{4} \mathrm{X}_{2}$-donor macrocyclic ligands $(\mathrm{X}=\mathrm{O}, \mathrm{NH}, \mathrm{S}$ or Se) are described. Distorted 8-coordination is evident from the crystal structure of the neutral $\left[\mathrm{Ybl}_{2}\left([18] \mathrm{aneO}{ }_{4} \mathrm{Se}_{2}\right)\right]$, forming the first reported example of $\mathrm{Yb}(\mathrm{II})$-selenoether coordination.

The chemistry of the lanthanides (4f elements) is dominated by the $3+$ oxidation state, ${ }^{1}$ and apart from the fluorides and oxides of $\mathrm{Pr}^{4+}$ and $\mathrm{Tb}^{4+}$, only cerium forms an extensive range of compounds in the $4+$ state. $^{1-3}$ For many years lower oxidation states were limited to some divalent samarium, europium and ytterbium complexes, and compounds such as $\mathrm{LaI}_{2}$ or GdS, which were formulated as "metallic" Ln(III) species with the extra electron delocalised in a conduction band. ${ }^{2}$ Early uses of $\mathrm{Eu}(\mathrm{II})$ as a one electron reductant were followed by the development of a similar role for $\mathrm{SmI}_{2}$ and $\left[\left(\mathrm{Cp}^{*}\right)_{2} \mathrm{Sm}(\mathrm{thf})_{2}\right]^{4}{ }^{4}$ Recent work aimed at developing suites of lanthanide(II) complexes with varying reactivities for use in organic reductions, couplings, polymerisation and dinitrogen activation has led to new organometallic complexes of all the $\mathrm{M}$ (II) (except for $\mathrm{Pm})$ as $[\mathrm{K}($ macrocycle $)]\left[\mathrm{Ln}\left(\mathrm{C}_{5} \mathrm{H}_{4} \mathrm{SiMe}_{3}\right)_{3}\right]$ (macrocycle $=18$-crown- 6 or 222-crypt), $\S$ although samarium(II) reagents remain the most widely used in organic chemistry. ${ }^{5}$

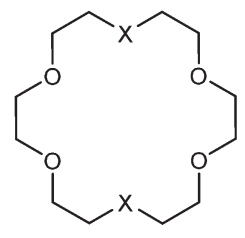

$\mathrm{X}=\mathrm{O} ; 18$-crown- 6

$\mathrm{X}=\mathrm{NH} ;[18] \mathrm{aneO}_{4} \mathrm{~N}_{2}$

$\mathrm{X}=\mathrm{S} ;[18] \mathrm{aneO}_{4} \mathrm{~S}_{2}$

$\mathrm{X}=\mathrm{Se} ;[18] \mathrm{aneO}_{4} \mathrm{Se}_{2}$

School of Chemistry, University of Southampton, Southampton SO17 1BJ, UK. E-mail:wxl@soton.ac.uk

$\dagger$ Dedicated to the memory of Professor Ken Wade FRS in recognition of his many contributions to inorganic chemistry.

\$Electronic supplementary information (ESI) available: Further experimental and crystallographic details for the structure of $\left[\mathrm{YbI}_{2}\left([18] \mathrm{aneO}_{4} \mathrm{Se}_{2}\right)\right]$. CCDC 1024072. For ESI and crystallographic data in CIF or other electronic format see DOI: $10.1039 / \mathrm{c} 4 \mathrm{dt} 03462 \mathrm{~g}$
We recently reported studies of Ln(III) complexes of oxa-thia, oxa-selena macrocycles and crown ethers, focused on La and Lu complexes, including X-ray structural characterisation of rare examples of Ln-thioether and the first examples of Ln-selenoether coordination. ${ }^{6}$ The metal iodides were used for much of this work, ${ }^{6}$ since for both the lanthanide and some early transition metal complexes ${ }^{7}$ the metal iodides are more soluble than lighter halide analogues in modestly polar organic solvents, presumably due to lower lattice energies, which facilitates synthesis and solution studies. Here we report studies of similar macrocyclic ligand complexes of ytterbium(II) iodide. The $\mathrm{f}^{14} \mathrm{Yb}$ (II) permits direct comparison with the isoelectronic Lu(III) complexes, ${ }^{6}$ as well as with recently reported complexes of these ligands with $\mathrm{Ca}$ and $\mathrm{Sr},{ }^{8}$ whilst its diamagnetism aids solution NMR studies.

Reaction of anhydrous $\mathrm{YbI}_{2}$ with the ligands 18-crown-6, [18] ane $\mathrm{a}_{4} \mathrm{~S}_{2}, \quad[18] \mathrm{aneO}_{4} \mathrm{Se}_{2}$ and [18] $\mathrm{aneO}_{4} \mathrm{~N}_{2}$ in anhydrous MeCN gave modest yields of white to pale yellow species, $\left[\mathrm{YbI}_{2}\right.$ (ligand)] (Scheme 1); the formulation was confirmed by microanalysis.

The IR spectra showed the presence of the ligand and absence of $\mathrm{MeCN}$ (and $\mathrm{H}_{2} \mathrm{O}$ ). The complexes are moderately soluble in anhydrous $\mathrm{MeCN}$, and very readily hydrolysed and oxidised by exposure to air. Very small crystals of $\left[\mathrm{YbI}_{2}([18]\right.$ ane $\left.\mathrm{O}_{4} \mathrm{Se}_{2}\right)$ ] were obtained after storing an MeCN solution of the complex in a freezer $\left(-18^{\circ} \mathrm{C}\right)$.

The complex has crystallographic two-fold symmetry and is isomorphous with $\left[\mathrm{CaI}_{2}\left([18] \mathrm{aneO}_{4} \mathrm{Se}_{2}\right)\right],{ }^{8}$ based upon hexadentate coordination of the macrocycle, with two mutually cis iodide ligands completing the distorted 8-coordination at $\mathrm{Yb}$ (II)

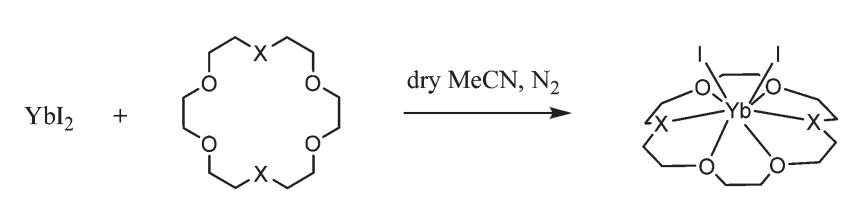

Scheme 1 


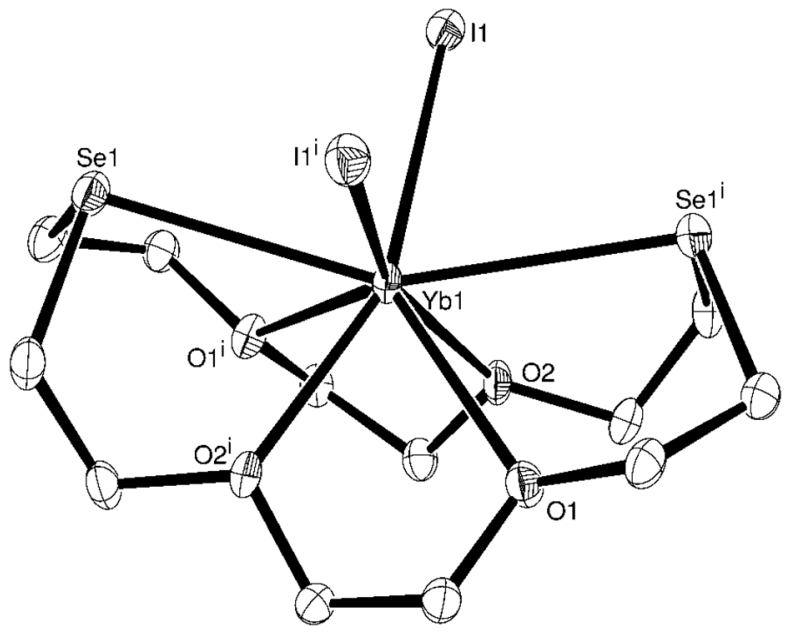

Fig. 1 View of the structure of $\left[\mathrm{Ybl}_{2}\left([18] \mathrm{aneO}_{4} \mathrm{Se}_{2}\right)\right]$ showing the atom labelling scheme. The displacement ellipsoids are drawn at the 50\% probability level and $\mathrm{H}$ atoms are omitted for clarity. Symmetry operation: $\mathrm{i}=-x, y, 1 / 2-z$. Selected bond lengths $(\AA \AA)$ and angles $\left({ }^{\circ}\right)$ : $\mathrm{Yb} 1-11=3.1699(5), \mathrm{Yb} 1-\mathrm{Se} 1=3.1036(7), \mathrm{Yb} 1-\mathrm{O} 1=2.624(3), \mathrm{Yb} 1-\mathrm{O} 2=$ 2.472(3), O1-Yb1-O1 ${ }^{\mathrm{i}}=117.98(14), \mathrm{O} 1-\mathrm{Yb} 1-\mathrm{O} 2$ = 76.42(10), $\mathrm{O}^{\mathrm{i}}-\mathrm{Yb} 1-$

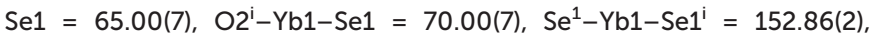
$11-Y b 1-\mid 1^{i}=100.488(19)$.

(Fig. 1). The bond lengths and angles are also very similar to the $\mathrm{Ca}$ (II) species. This is as expected given their similar ionic radii $\left(\mathrm{Yb}^{2+}=1.16 \AA, \mathrm{Ca}^{2+}=1.14 \AA\right){ }^{9}$. The neutral $\left[\mathrm{YbI}_{2}([18]-\right.$ ane $\left.\left.\mathrm{O}_{4} \mathrm{Se}_{2}\right)\right]$ molecule is also structurally very similar to the cation in the isoelectronic $\left[\mathrm{LuI}_{2}\left([18] \mathrm{aneO}_{4} \mathrm{Se}_{2}\right)\right] \mathrm{I} \cdot 2 \mathrm{MeCN},{ }^{6}$ albeit with slightly shorter corresponding bonds (by 0.1-0.15 $\AA$ ) in the latter, reflecting the smaller radius resulting from the higher charge $\left(\mathrm{Lu}^{3+}\right.$ ionic radius $\left.1.00 \AA\right)$. In the $\mathrm{Yb}$ (II) complex, the Se-M-Se angle is some $13^{\circ}$ wider than in the $\mathrm{Lu}(\mathrm{III})$ analogue, and the $\mathrm{I}-\mathrm{M}-\mathrm{I}$ angle $\sim 5^{\circ}$ wider. The larger $\mathrm{La}^{3+}$ ion (ionic radius $\left.=1.22 \AA\right)^{9}$ forms nine-coordinate $\left[\operatorname{LaI}_{3}(\right.$ macrocycle) $]$ with these hexadentate macrocycles. ${ }^{6}$

Although we were unable to obtain diffraction-quality crystals of $\left[\mathrm{YbI}_{2}\left(18\right.\right.$-crown-6)], $\left[\mathrm{YbI}_{2}\left([18] \mathrm{aneO}_{4} \mathrm{~S}_{2}\right)\right]$ or $\left[\mathrm{YbI}_{2}([18]-\right.$ aneO $\left.\left.\mathrm{O}_{4} \mathrm{~N}_{2}\right)\right]$, on the basis of microanalytical and spectroscopic data it seems highly probable that they also contain eightcoordinate $\mathrm{Yb}(\mathrm{II})$.

The complexes are very poorly soluble in $\mathrm{CH}_{2} \mathrm{Cl}_{2}$, however, they are moderately soluble in MeCN, affording yellow solutions. ${ }^{1} \mathrm{H}$ NMR spectra of $\left[\mathrm{YbI}_{2}\left([18] \mathrm{aneO}_{4} \mathrm{~S}_{2}\right)\right]$ and $\left[\mathrm{YbI}_{2}([18]-\right.$ aneO $\left.\left.\mathrm{O}_{4} \mathrm{Se}_{2}\right)\right]$ in anhydrous $\mathrm{CD}_{3} \mathrm{CN}$ show broad $\mathrm{OCH}_{2}$ and $\mathrm{S}(\mathrm{Se}) \mathrm{CH}_{2}$ resonances, with smaller coordination shifts than observed in the corresponding $\mathrm{Lu}(\mathrm{III})$ cations. ${ }^{6}$ We were unable to observe a ${ }^{77} \mathrm{Se}$ NMR resonance from $\left[\mathrm{YbI}_{2}\left([18] \mathrm{aneO}_{4} \mathrm{Se}_{2}\right)\right]$, contrasting with $\left[\mathrm{LuI}_{2}\left([18] \mathrm{aneO}_{4} \mathrm{Se}_{2}\right)\right] \mathrm{I}$ which exhibited a sharp resonance with a low frequency coordination shift $(\Delta)$ of $-32 \mathrm{ppm}$. The NMR data are consistent with the macrocycles exhibiting dynamic processes in solution and weaker binding to the $\mathrm{Yb}$ (II), compared with the isoelectronic Lu(III) analogues. In $10^{-3} \mathrm{~mol} \mathrm{dm}^{-3}$ solutions in anhydrous MeCN, the complexes have high molar conductivities, in the range characteristic of $1: 2$ electrolytes, ${ }^{10}$ which suggests that like the $\operatorname{Ln}(\mathrm{III})$ analogues, ${ }^{6}$ the iodide ligands are displaced by $\mathrm{MeCN}$ in dilute solution, although MeCN is not present in the solid complexes isolated from this solvent.

Cyclic voltammetry experiments were performed to probe the redox responses from these complexes. Owing to their poor solubility in non-coordinating solvents such as $\mathrm{CH}_{2} \mathrm{Cl}_{2}$, electrochemistry experiments were initially attempted using $0.1 \mathrm{~mol} \mathrm{dm}^{-3}\left[\mathrm{~N}^{n} \mathrm{Bu}_{4}\right] \mathrm{I}$ in anhydrous MeCN as supporting electrolyte. However, the presence of excess iodide significantly suppressed the solubility of the complexes. Therefore, subsequent experiments used $0.1 \mathrm{~mol} \mathrm{dm}{ }^{-3}\left[\mathrm{~N}^{n} \mathrm{Bu}_{4}\right]\left[\mathrm{BF}_{4}\right]-\mathrm{MeCN}$ as supporting electrolyte. Under these conditions the complexes each show voltammetric peaks attributed to the electrooxidation of free iodide. The relative peak heights indicated the liberation of one iodide ion per $\mathrm{Yb}$ (II) complex. No other peaks associated with $\mathrm{Yb}(\mathrm{II}) /(\mathrm{III})$ redox couples were evident under these conditions over the potential range -2 to $+1.5 \mathrm{~V}$.

\section{Experimental}

Details of the spectroscopic and electrochemical measurements and X-ray crystallography are given in the ESI.\$

\section{Synthesis}

[YbI 2 (18-crown-6)]. $\mathrm{YbI}_{2}(0.075 \mathrm{~g}, 0.176 \mathrm{mmol})$ was dissolved in acetonitrile $(10 \mathrm{~mL}) .18$-crown-6 $(0.047 \mathrm{~g}, 0.176 \mathrm{mmol})$ dissolved in acetonitrile $(10 \mathrm{~mL})$ was then added and the reaction mixture was stirred for $c a .10 \mathrm{~min}$. The solvent was removed in vacuo and the residual very pale yellow solid was washed with hexane $(10 \mathrm{~mL})$ and dried in vacuo. Yield $0.102 \mathrm{~g}, 84 \%$. Required for $\mathrm{C}_{12} \mathrm{H}_{24} \mathrm{I}_{2} \mathrm{O}_{6} \mathrm{Yb}$ (691.2): C, 20.85.19; H, 3.50. Found C, $21.02 ; \mathrm{H}, 3.39 \% .{ }^{1} \mathrm{H}$ NMR $\left(\mathrm{CD}_{3} \mathrm{CN}, 300 \mathrm{~K}\right): \delta 3.80(\mathrm{~s}) \mathrm{ppm}$. $\Lambda_{\mathrm{M}}\left(\mathrm{MeCN} 10^{-3} \mathrm{~mol} \mathrm{dm}^{-3}\right)=189 \Omega^{-1} \mathrm{~cm}^{2} \mathrm{~mol}^{-1}$.

$\left[\mathrm{YbI}_{2}\left([\mathbf{1 8}] \mathbf{a n e O}_{4} \mathbf{S}_{2}\right)\right] . \mathrm{YbI}_{2}(0.050 \mathrm{~g}, 0.117 \mathrm{mmol})$ was dissolved in acetonitrile $(10 \mathrm{~mL}) .[18] \mathrm{aneO}_{4} \mathrm{~S}_{2}(0.035 \mathrm{~g}$, $0.117 \mathrm{mmol})$ also dissolved in acetonitrile $(10 \mathrm{~mL})$ was then added and the reaction mixture was stirred for $c a .10 \mathrm{~min}$. After reducing the solvent volume by a quarter in vacuo, toluene $(20 \mathrm{~mL})$ was added. This led to precipitation of a small amount of off-white precipitate. The flask was then placed in the freezer for $c a .2 \mathrm{~h}$ which increased the amount of precipitate. This was collected by filtration and dried in vacuo. Yield: $0.030 \mathrm{~g}, 36 \%$. Required for $\mathrm{C}_{12} \mathrm{H}_{24} \mathrm{I}_{2} \mathrm{O}_{4} \mathrm{~S}_{2} \mathrm{Yb}$ (723.3): C, 19.93; $\mathrm{H}, 3.34$. Found C, $19.82 ; \mathrm{H}, 3.26 \% .{ }^{1} \mathrm{H}$ NMR $\left(\mathrm{CD}_{3} \mathrm{CN}, 300 \mathrm{~K}\right): \delta$ $3.80\left(\right.$ br s, $\left.[16 \mathrm{H}] \mathrm{OCH}_{2}\right), 2.80\left(\mathrm{br} \mathrm{s},[8 \mathrm{H}], \mathrm{SCH}_{2} \mathrm{CH}_{2} \mathrm{O}\right) \mathrm{ppm} . \Lambda_{\mathrm{M}}$ $\left(\mathrm{MeCN} 10^{-3} \mathrm{~mol} \mathrm{dm}^{-3}\right)=220 \Omega^{-1} \mathrm{~cm}^{2} \mathrm{~mol}^{-1}$.

$\left[\mathbf{Y b I}_{2}\left([18] \mathbf{a n e O}_{4} \mathrm{Se}_{2}\right)\right]$. Made similarly to the $[18] \mathrm{aneO}_{4} \mathrm{~S}_{2}$ complex above, using $\mathrm{YbI}_{2}(0.050 \mathrm{~g}, 0.117 \mathrm{mmol})$ and [18]aneO$_{4} \mathrm{Se}_{2}(0.046 \mathrm{~g}, 0.117 \mathrm{mmol})$. Pale yellow solid. Yield: $0.030 \mathrm{~g}, 32 \%$. Required for $\mathrm{C}_{12} \mathrm{H}_{24} \mathrm{I}_{2} \mathrm{O}_{4} \mathrm{Se}_{2} \mathrm{Yb}$ (817.1): C, 17.64; $\mathrm{H}, 2.96$. Found C, $17.49 ; \mathrm{H}, 2.85 \%$. ${ }^{1} \mathrm{H}$ NMR $\left(\mathrm{CD}_{3} \mathrm{CN}, 300 \mathrm{~K}\right)$ : $\delta 3.83$ (br t, $J=6 \mathrm{~Hz},[8 \mathrm{H}], \mathrm{SeCH}_{2} \mathrm{CH}_{2} \mathrm{O}$ ), 3.72 (s, [8H], $\left.\mathrm{OCH}_{2} \mathrm{CH}_{2} \mathrm{O}\right), 2.84\left(\mathrm{t}, J=6 \mathrm{~Hz},[8 \mathrm{H}], \mathrm{SeCH}_{2} \mathrm{CH}_{2} \mathrm{O}\right) \mathrm{ppm} .{ }^{77} \mathrm{Se}$ NMR $\left(\mathrm{CH}_{3} \mathrm{CN}, 295 \mathrm{~K}\right.$ and $\left.230 \mathrm{~K}\right)$ : not observed. Crystals were obtained by storing an MeCN solution of the complex for 
several weeks in a freezer at $-18{ }^{\circ} \mathrm{C} . \Lambda_{\mathrm{M}}\left(\mathrm{MeCN} 10^{-3} \mathrm{~mol}\right.$ $\left.\mathrm{dm}^{-3}\right)=255 \Omega^{-1} \mathrm{~cm}^{2} \mathrm{~mol}^{-1}$.

$\left[\mathbf{Y b I}_{2}\left([18] \mathbf{a n e O}_{4} \mathbf{N}_{2}\right)\right] \cdot \mathrm{YbI}_{2}(0.050 \mathrm{~g}, 0.117 \mathrm{mmol})$ was dissolved in acetonitrile $(10 \mathrm{~mL}) . \quad[18] \mathrm{aneO}_{4} \mathrm{~N}_{2}(0.031 \mathrm{~g}$, $0.117 \mathrm{mmol})$ was also dissolved in acetonitrile $(10 \mathrm{~mL})$ and added to the $\mathrm{YbI}_{2}$ solution. The reaction mixture was stirred for ca. $10 \mathrm{~min}$. by which time a small amount of pale yellow precipitate had formed. The solvent volume was reduced by $50 \%$ in vacuo, increasing the amount of precipitate. This was then collected by filtration and dried in vacuo. Yield: $0.044 \mathrm{~g}$, $54 \%$. Required for $\mathrm{C}_{12} \mathrm{H}_{26} \mathrm{I}_{2} \mathrm{~N}_{2} \mathrm{O}_{4} \mathrm{Yb}$ (689.2): C, 20.91; H, 3.80, $\mathrm{N}, 4.06$. Found: C, 20.87; H, 3.73; N, 4.13\%. IR (Nujol mull): $3220 \mathrm{~cm}^{-1}$ ขNH. ${ }^{1} \mathrm{H}$ NMR $\left(\mathrm{CD}_{3} \mathrm{CN}, 300 \mathrm{~K}\right): \delta 3.78$ (v.br m, [8H] $\mathrm{OCH}_{2}$ ), 3.59 (v.br m, [8H] $\mathrm{OCH}_{2} \mathrm{CH}_{2} \mathrm{~N}$ ), 2.95 (v.br s, [4H] $\mathrm{CH}_{2} \mathrm{~N}$ ), 2.68 (v.br s, [4H], $\mathrm{CH}_{2} \mathrm{~N}$ ), 2.40 (v.br s, [2H], NH) ppm. $\Lambda_{\mathrm{M}}\left(\mathrm{MeCN} 10^{-3} \mathrm{~mol} \mathrm{dm}{ }^{-3}\right)=225 \Omega^{-1} \mathrm{~cm}^{2} \mathrm{~mol}^{-1}$.

\section{Conclusions}

The synthesis, spectroscopic and structural characterisation of rare heterocrown complexes of a divalent lanthanide, specifically $\mathrm{Yb}$ (II), has been achieved. Coordination of soft thioether and selenoether functions to $\mathrm{Yb}(\mathrm{II})$ has been demonstrated. The properties of these complexes are intermediate between those of $\mathrm{Ln}(\mathrm{III})$ and $\mathrm{Ca}(\mathrm{II}) / \mathrm{Sr}$ (II) analogues. More generally, although the coordination of the soft donors is clearly aided by the presence of O-donors in the macrocycle, the study suggests that a wider range of coordination complexes derived from divalent lanthanides with neutral ligands, including other soft Lewis bases, should be accessible with judicious choice of solvent, reaction conditions and anion.

\section{Acknowledgements}

We thank EPSRC for support (EP/1033394/1). The SCFED Project (http://www.scfed.net) is a multidisciplinary collaboration of British universities investigating the fundamental and applied aspects of supercritical fluids.

\section{Notes and references}

$\S[18] \mathrm{aneO}_{4} \mathrm{~S}_{2}=$ 1,4,10,13-tetraoxa-7,16-dithiacyclooctadecane, [18] $\mathrm{aneO}_{4} \mathrm{Se}_{2}=$ 1,4,10,13-tetraoxa-7,16-diselenacyclooctadecane, [18]ane $\mathrm{N}_{2} \mathrm{O}_{4}=1,4,10,13$-tetraoxa-7,16-diazacyclooctadecane, 18-crown-6 = 1,4,7,10,13,16-hexaoxacyclooctadecane.

1 S. Cotton, in Comprehensive Coordination Chemistry II, ed. J. A. McCleverty and T. J. Meyer, Elsevier, Oxford, 2004, vol. 4 , p. 93.

2 D. A. Johnson, Adv. Inorg. Chem. Radiochem., 1977, 20, 1.

3 N. A. Piro, J. R. Robinson, P. J. Walsh and E. J. Schelter, Coord. Chem. Rev., 2014, 260, 21.

4 (a) W. J. Evans, Coord. Chem. Rev., 2000, 206-207, 263; (b) M. N. Bochkarev, Coord. Chem. Rev., 2004, 248, 835.

5 (a) M. Szostak and D. J. Procter, Angew. Chem., Int. Ed., 2012, 51, 9238; (b) M. R. MacDonald, J. E. Bates, J. W. Ziller, P. Furche and W. J. Evans, J. Am. Chem. Soc., 2013, 135, 9857.

6 M. J. D. Champion, P. Farina, W. Levason and G. Reid, Dalton Trans., 2013, 42, 13179.

7 (a) W. Levason, M. L. Matthews, B. Patel, G. Reid and M. Webster, Dalton Trans., 2004, 3305; (b) S. D. Reid, A. L. Hector, W. Levason, G. Reid, B. J. Waller and M. Webster, Dalton Trans., 2007, 4769.

8 P. Farina, W. Levason and G. Reid, Dalton Trans., 2013, 42, 89.

9 F. A. Cotton, G. Wilkinson, C. A. Murillo and M. Bochmann, Advanced Inorganic Chemistry, Wiley, New York, 6th edn, 1999.

101 : 1 Electrolytes have $\Lambda_{\mathrm{M}}\left(\mathrm{MeCN} 10^{-3} \mathrm{~mol} \mathrm{dm}^{-3}\right) \sim 120-160$ and $1: 2$ electrolytes $\sim 220-300 \Omega^{-1} \mathrm{~cm}^{2} \mathrm{~mol}^{-1}$. W. J. Geary, Coord. Chem. Rev., 1971, 6, 81. 